\title{
Habitar Coletivo: \\ obras diferenciadas contemporâneas em São Paulo'
}

\author{
Fabricia Zulin, \\ Rafael Antonio Perrone*
}

Resumo Este trabalho apresenta um estudo de obras diferenciadas de habitação coletiva do início do século XXI localizadas na região metropolitana de São Paulo. Denominar esses estudos de caso como diferenciados, revela-se positivo pelo fato de contribuírem com novas possibilidades de agentes, de ocupação de lote urbano, novas técnicas construtivas, novas maneiras de agenciamento do programa entre outras possibilidades reveladas, muitas vezes rebaixadas na produção comercial usual. No artigo será exposta a leitura de um dos casos estudados, Vila Fidalga, da arquiteta Cristina Xavier, projeto em que sua participação efetiva em todo processo reflete na boa arquitetura resultante.

Palavras-chave: habitação coletiva, arquitetura contemporânea, pesquisa em Projeto de Arquitetura.

\section{Habitar colectivo: obras diferenciadas con- temporáneas en São Paulo}

Resumen Este trabajo presenta un estudio de obras diferenciadas de vivienda colectiva de principios del siglo XXI ubicadas en la región metropolitana de São Paulo. Denominar los estudios de caso como diferenciados, se muestra positivo por el hecho de que contribuyen con nuevas posibilidades de agentes, de ocupación de lote urbano, nuevas técnicas constructivas, nuevas formas de agenciamiento del programa entre otras posibilidades reveladas, muchas veces rebajadas en la producción comercial usual. En el artículo se expondrá la lectura de uno de los casos estudiados, Vila Fidalga, de la arquitecta Cristina Xavier, proyecto en que su participación efectiva en todo proceso refleja en la buena arquitectura resultante.

Palabras clave: vivienda colectiva, arquitectura contemporánea, investigación en Proyecto de Arquitectura.

\section{Collective Housing: a contemporary and differential proposals in São Paulo}

\begin{abstract}
This work presents a study of differentiated proposals of collective housing from the beginning of the XXI century located in the metropolitan region of São Paulo. To denominate these case studies as differentiated, it is positive because they contribute with new possibilities of agents, occupation of urban lot, new constructive techniques, new ways of agency of the program among other possibilities revealed, often lowered in the usual commercial production. In the article will be exposed the reading of one of the cases studied, Vila Fidalga, by the architect Cristina Xavier, project in which its effective participation in all processes reflects in the good architecture that results.
\end{abstract}

Keywords: collective housing, contemporary architecture, research in Architecture Project. 
A

pesquisa partiu de uma pergunta ampla inicial: O que está sendo realizado com qualidade nos últimos anos no âmbito da habitação coletiva? Ou ainda: Onde estão os bons projetos em meio a tanta mesmice? Em um primeiro momento não foram estabelecidos critérios claros e bem definidos para seleção dos projetos a serem estudados. Muito menos foi um processo irracional ou aleatório, contando inicialmente com a percepção, intuição e o "olho" da jovem arquiteta pesquisadora, que foi sendo treinado ao longo da pesquisa, afinal, alcançar a mínima visão seletiva e apurada com relação à distinção entre uma arquitetura com ou sem qualidade, é uma habilidade que exige tempo, dedicação e paciência.

Conjuntamente com o método intuitivo descrito acima, a seleção do primeiro grupo de projetos para a pesquisa, apoiou-se na triagem que as próprias revistas especializadas em arquitetura e urbanismo já realizam naturalmente, afinal, publicam projetos de bons escritórios de arquitetura, inclusive muitos deles premiados, sendo que, a partir do momento em que são divulgados ou publicados nos canais de comunicação, se tornam públicos e entram na pauta de discussão principalmente entre os(as) arquitetos(as) e estudantes de arquitetura. TEPERMAN (2009) relata sobre o processo de seleção de projetos em revistas especializadas, sobre a falta de explicação racional ou ausência de parâmetros claros para definição da boa arquitetura:

Há algum tempo nossa editora sugeriu-me um tema para o artigo, sobre o que é boa arquitetura. É surpreendente notar que as editoras de revistas de arquitetura e interiores no Brasil (é curioso, são quase todas mulheres que não são arquitetas), pelo seu contato diário com a nossa profissão, publicam obras que são na média (e na mídia) boa arquitetura, muito embora nem essas editoras saibam o porquê de as terem escolhido. (TEPERMAN, 2009, p. 79)

Deste modo, foi conjugado ao processo de seleção as publicações de importantes revistas de arquitetura e urbanismo do Brasil - ProjetoDesign e Arquitetura e Urbanismo, onde foram encontradas mais de cem obras de habitação coletiva no período de dezembro de 1999 até junho de 2011 de diversas partes do Brasil e do mundo e por agentes promotores variados ${ }^{2}$.

\footnotetext{
* Fabricia Zulin é Arquiteta e Urbanista, doutoranda em Arquitetura e Urbanismo pela Universidade de São Paulo, ORCID <http://orcid. org/0000-0003-1043-1704>. Rafael Antonio Perrone é Arquiteto e Urbanista, professor da Faculdade de Arquitetura e Urbanismo da Universidade de São Paulo, ORCID <http://orcid. org/0000-0003-0651-913X>.
}

Num segundo momento da pesquisa, houve um processo de filtragem da primeira seleção, mantendo as obras construídas, localizadas na América Latina, e aquelas mais relacionadas ao lote ou quadra urbana onde estão inseridas. Uma hipótese inicial foi de que muitos projetos na cidade, considerados sem qualidade arquitetônica, eram projetos muito similares ou representavam meras replicações de padrões ditados pelo mercado imobiliário. Deste modo, foi levantada a suposição de que lotes urbanos pequenos, irregulares, com topografia acidentada entre outros condicionantes relevantes do lote, seriam aqueles com maiores restrições para implantação de tipologias "carimbos", em sua maioria, promovidas por grandes incorporadoras do mercado imobiliário. 
1 Artigo resultante da dissertação de mestrado, em ZULIN (2013), intitulada Habitar Coletivo: Obras diferenciadas contemporâneas em São Paulo, orientada pelo Prof. Dr. Rafael Antonio Cunha Perrone, defendida na Faculdade de Arquitetura e Urbanismo da Universidade de São Paulo no ano de 2013.

2 Os projetos identificados nas revistas podem ser consultados em ZULIN (2013), Apêndice 01, dissertação de mestrado base referencial para este artigo.

3 Os projetos identificados nas revistas podem ser consultados em ZULIN (2013), Apêndice 02, da dissertação de mestrado base referencial para este artigo.
Depois se somou a esta questão da especificidade da inserção urbana outros condicionantes também importantes, como os agentes promotores, o programa, as técnicas construtivas e, inclusive, o papel do(a) arquiteto(a) no processo como um todo.

Diferentemente do que se imaginava inicialmente, até mesmo nas revistas especializadas são publicados alguns projetos voltados para o segmento comercial, contratados por grandes clientes conhecidos do mercado imobiliário. Assim, os projetos, que num primeiro olhar pareciam ter o partido do empreendimento definido e conduzido pelo agente incorporador imobiliário, foram descartados da pesquisa. Deste modo, ficou nítido que não se tratava de uma seleção que partiria apenas de bons arquitetos(as) ou bons escritórios de arquitetura, como também, de clientes não convencionais entre outros condicionantes que colaboram positivamente com o resultado final e, consequentemente, tornam os projetos diferenciados e com qualidades. Assim, o que se buscava naquele momento, eram arquiteturas com ideias que se diferenciassem das propostas correntes oferecidas pelo mercado imobiliário, que predominam nas grandes cidades, inclusive São Paulo. Neste caminho, foram selecionados trinta e quatro projetos, apresentados na banca de qualificação que ocorreu em fevereiro de $2012^{3}$.

Numa fase final da dissertação foram mantidos apenas os projetos da Região Metropolitana de São Paulo (RMSP), pela facilidade de visita e registro fotográfico, pelas oportunidades de contato direto com os(as) arquitetos(as) autores(as) dos projetos e agentes, incluindo obtenção de material gráfico para as análises necessárias (arquivos digitais para edição) e também, pela coerência maior de algumas comparações entre os projetos, em alguns temas relacionados à localização dos mesmos. Assim, foi obtida uma pequena amostra de obras de habitação coletiva contemporânea na região metropolitana de São Paulo do século XXI, representada por oito projetos, com qualidade arquitetônica superior a encontrada na produção usual do mercado imobiliário. Consequentemente, surgiram situações de projetos onde os agentes são os(as) próprios(as) arquitetos(as) ou por demanda de clientes especiais, como será notado ao longo do trabalho.

Os oito projetos selecionados (Figura 1) para uma leitura e análise mais precisa foram:

- Conjuntos Residenciais Horizontais: Vila Butantã (Arquiteto Marcos Acayaba); Vila Fidalga (Arquiteta Cristina Xavier); Canaã (Arquitetos Joan Villà e Sílvia Chile) e Vila Taguaí (Arquiteta Cristina Xavier e Engenheiro Hélio Olga);

- Edifícios pouco verticalizados com unidades habitacionais sobrepostas: Vila Pedro Fachini (Arquitetos Marcelo Barbosa e Jupira Corbucci) e Fiori di Maggio (Arquitetos Carlos Ferrata, Apoena e Moracy Amaral, Eduardo Ferroni e Pablo Hereñú);

- Edifícios verticalizados com unidades habitacionais sobrepostas: Fidalga 772 (Arquitetos Andrade Morettin) e Simpatia 234 (Grupo SP).

Ao longo das leituras dos projetos e também nas comparações finais realizadas na última parte da pesquisa, outros projetos são citados, de modo a colaborar com o entendimento das diversas situações expostas. O mapa abaixo indica a localização dos estudos de casos principais e secundários: 

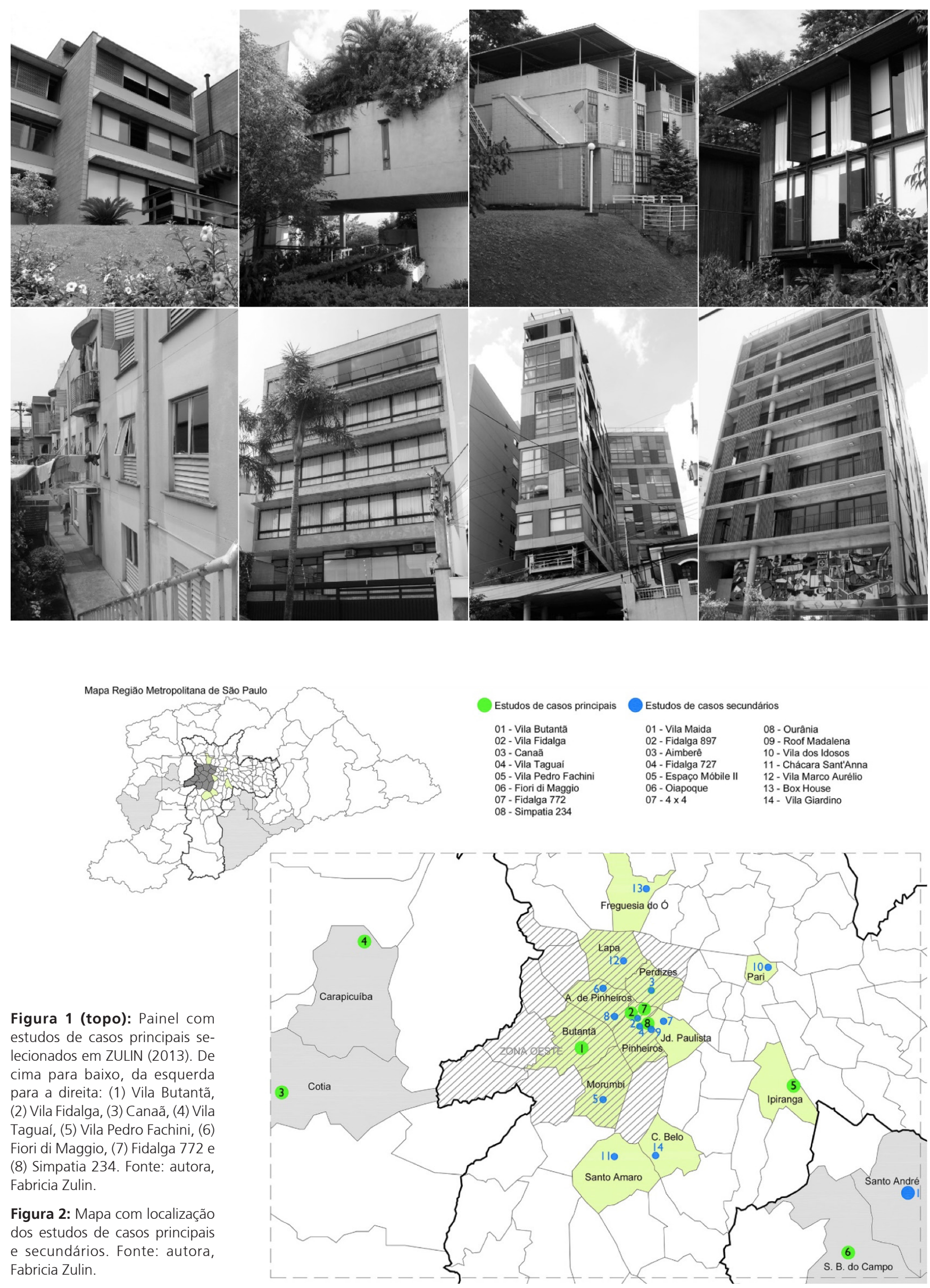

Figura 1 (topo): Painel com estudos de casos principais selecionados em ZULIN (2013). De cima para baixo, da esquerda para a direita: (1) Vila Butantã, (2) Vila Fidalga, (3) Canaã, (4) Vila Taguaí, (5) Vila Pedro Fachini, (6) Fiori di Maggio, (7) Fidalga 772 e (8) Simpatia 234. Fonte: autora, Fabricia Zulin.

Figura 2: Mapa com localização dos estudos de casos principais e secundários. Fonte: autora, Fabricia Zulin.

\begin{tabular}{lll} 
Estudos de casos principais & \multicolumn{2}{c}{ Estudos de casos secundários } \\
01 - Vila Butantă & 01 - Vila Maida & 08 - Ourânia \\
$02-$ Vila Fidalga & 02 - Fidalga 897 & 09 - Roof Madalena \\
03 - Canaã & 03 - Aimberê & 10 - Vila dos Idosos \\
04 - Vila Taguaí & 04 - Fidalga 727 & 11 - Chácara Sant'Anna \\
05 - Vila Pedro Fachini & 05 - Espaço Móbile II & 12 - Vila Marco Aurélio \\
06 - Fiori di Maggio & 06 - Oiapoque & 13 - Box House \\
07 - Fidalga 772 & $07-4 \times 4$ & 14 - Vila Giardino \\
08 - Simpatia 234 & &
\end{tabular}


4 LEI No 11.605, de 12 de Julho de 1994 - Dispõe sobre a criação da subcategoria de uso residencial R3-03, conjunto residencial - vila, e dá outras providências.

\footnotetext{
5Idea!Zarvos é uma incorporadora diferenciada que foi fundada por Otavio Zarvos, em 2005, muito influenciado pela sua mulher, estilista argentina, Magdalena Zarvos, no sentido da preocupação com a estética conjugada ao impacto positivo no entorno e na cidade. O histórico da empresa pode ser consultado no próprio site, disponível em: <http:// ideazarvos.com.br/pt/historia/>. Acesso em 10 de janeiro de 2018.
}

Enquanto estrutura do trabalho, foram realizadas leituras individuais, de cada estudo de caso principal selecionado, que trazem contribuições diversas para o tema da habitação coletiva contemporânea. Representam uma amostra, pois, conseguem expor apenas algumas maneiras de atuação na cidade, não todas. Para o presente artigo será exposto o caso da Vila Fidalga, obra excepcional por vários motivos, que vão desde a definição clara dos espaços coletivos e privativos na implantação, até a própria posição da arquiteta de tomar as rédeas do próprio negócio e assumir um empreendimento por completo, situação que reflete na boa arquitetura resultante.

Após a realização da leitura individual de cada projeto, foram realizadas algumas conclusões entre os projetos dentro das temáticas presentes nas leituras individuais dos estudos de casos: Inserção Urbana (no entorno imediato e lote urbano), Espaços exteriores, Sistema Estrutural e Técnica Construtiva, Envoltória, Unidade Habitacional e Agentes. Para o presente artigo será exposta parcialmente a temática da inserção em lote urbano de modo a demonstrar a metodologia e alguns resultados obtidos a partir dos estudos de casos.

\section{Vila Fidalga}

É destaque na Vila Fidalga a diferença com relação a outros projetos também possibilitados pela Lei de Vilas (1994) ${ }^{4}$, onde geralmente implantam-se casas isoladas, com recuos mínimos entre elas e com deficiência na resolução dos espaços coletivos em relação aos privativos. Neste projeto, a insolação, orientação e vistas mais interessantes fez com que cada unidade fosse diferente uma da outra, e isto é bastante significativo. Além de considerar as especificidades de cada parcela do lote, também foi importante enquanto conceito da implantação, a definição dos espaços coletivos que balizam os limites dos privativos, de tal modo a garantir o bem-estar individual e coletivo. Por outro lado, os espaços privativos foram concebidos de modo a possibilitar a personalização interna das unidades, dentro das regras de um projeto desenvolvido para atender alguns desejos individuais dos moradores.

Assim, a autonomia que a arquiteta adquire, por ser também a agente empreendedora, reflete na boa arquitetura resultante, que não deixa de ser um produto de arquitetura para competição no mercado imobiliário:

É uma tentativa de abrir espaço para produtos de arquitetura no mercado imobiliário da cidade. Abrir espaço para que moradores, profissionais de projeto e construção e incorporadores fossem considerados com o devido cuidado e respeito para que o produto final pudesse ser uma contribuição ao bem estar individual e coletivo. Abrir espaço, encontrar um canto, uma brecha para construir valores, sobre valores, humanos. (XAVIER, 2001)

\section{Agentes}

É difícil expor o estudo de caso da Vila Fidalga sem antes citar um projeto anterior da arquiteta, o Condomínio Fidalga 897 (Figura 3), experiência embrião sequenciada no projeto da Vila Fidalga e nos projetos da Idea!Zarvos ${ }^{5}$ no sentido de dar possibilidade de personalização das unidades habitacionais. 


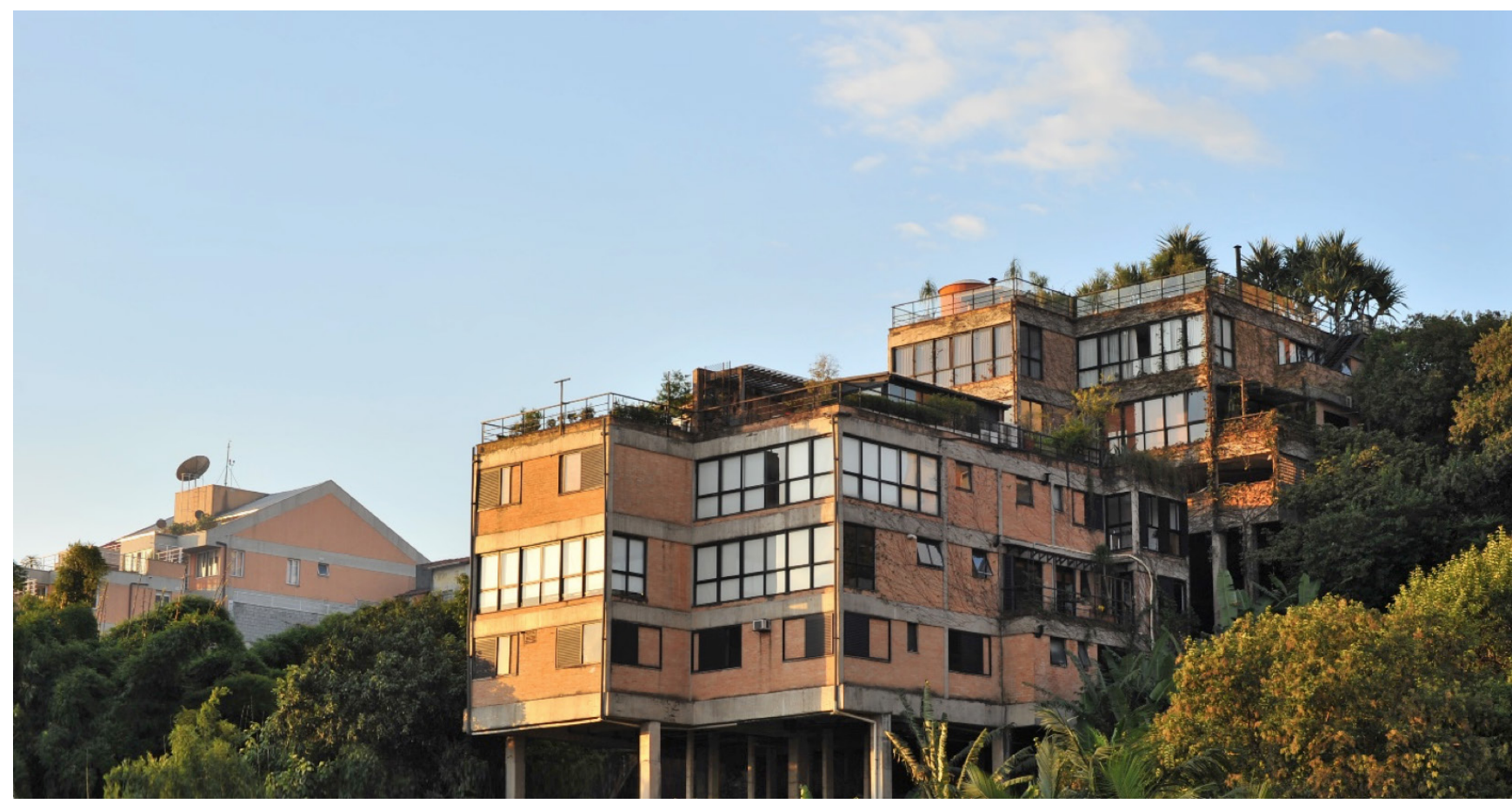

Figura 3: Condomínio Fidalga 897. Fonte: acervo Cristina Xavier.

6 O Condomínio Fidalga 897 foi realizado em 1996. A arquiteta Cristina Xavier foi contratada pela Zarvos Engenharia, na época dirigida pelos irmãos Fábio e Otávio Zarvos, para realizar o projeto arquitetônico. É um conjunto formado por dez unidades habitacionais. A personalização das unidades foi levada ao extremo tendo cada morador seu projeto.

7 Expressão utilizada por WISNIK (2002).
É possível entender que a realização do projeto de arquitetura do Fidalga $897^{6}$ e sua participação no processo de atendimento aos clientes, propiciou Cristina Xavier a uma posterior reflexão sobre a qualidade do projeto de arquitetura dentro de um processo maior no mercado imobiliário e sobre quais pontos o projeto deveria se proteger mais para conseguir resguardar sua essência e qualidade, isto quer dizer, não deixar que o processo de personalização das unidades conjuntamente com os moradores ultrapassasse limites, de tal forma a não permitir que o desejo individual prevaleça sobre o coletivo. Este resgate à experiência anterior da arquiteta é importante, pois o avanço do segundo projeto da Rua Fidalga com relação ao primeiro, é justamente de o espaço coletivo estar firme o suficiente para limitar os espaços privativos, ou seja, "o espaço coletivo como baliza" 7 .

Assim em 1999; em parceria com Filipe Xavier (seu irmão), Francisco Limongi e Sônia Mindlin; a arquiteta fundou a Taguaí Arquitetura e Incorporação, para realização completa da Vila Fidalga. O engenheiro Hélio Olga Júnior, que estava realizando a Vila Butantã com o arquiteto Marcos Acayaba na época (outro empreendimento em que arquiteto e engenheiro são agentes empreendedores do próprio projeto), foi contratado pela Taguaí para ser o responsável pela construção, enquanto sua irmã, Hebe Olga de Souza, foi a arquiteta que colaborou no acompanhamento da execução da obra da vila.

A arquiteta Cristina Xavier, como sócia da Taguaí, conseguiu ter uma participação efetiva em todas as etapas do processo, que é mais amplo do que a fase de projeto, englobando desde a busca e negociação do terreno, aprovação do projeto legal, construção, incorporação e venda das unidades. Este projeto tem o potencial de informar ao público sobre a existência de outras soluções projetuais e de incorporação que não sejam aquelas repetidas pela cidade, retomando, assim, a discussão sobre a relação entre arquitetura e mercado. 


\section{Inserção urbana}

O projeto é uma realização de possibilidades abertas com a Lei das Vilas, que viabilizou a construção de condomínios em lotes individuais, situados em zonas em que se permite pouca verticalização. Nesse sentido, a comparação da solução proposta pela arquiteta com as adotadas na maior parte dos condomínios fechados recentes, e que resultaram da mesma lei, é elucidadora. (WISNIK, 2002)

A construção deste conjunto de casas - em um único lote, que possivelmente abrigaria uma residência unifamiliar, ou permaneceria vazio devido a sua topografia acidentada, numa zona que se permite pouca verticalização - só foi possível com a criação da Lei de Vilas em 1994 (Figura 4).

O terreno íngreme e irregular onde foi implantada a Vila Fidalga representava um espaço vazio e residual no bairro, um verdadeiro retalho urbano antes da implantação do conjunto de seis casas. Possui acesso por viário inclinado e está ao lado da Praça José Carlos Burle, onde funciona uma Escola Municipal. Parece extensão desta praça, seja pela quantidade de área verde presente entre as casas, seja pela cuidadosa inserção na topografia e meio natural.

Neste trecho, a Rua Fidalga está aproximadamente dez metros acima da cota da Rua Fradique Coutinho, além disso, desde a face noroeste da vila, pode-se avistar o bairro Alto de Pinheiros, a Praça Dolores Ibarruri (de onde é possível observar o conjunto à distância), e o Vale do Córrego das Corujas, que separa a Vila Madalena da Vila Beatriz.
Figura 4: Destaque da inserção da Vila Fidalga na paisagem Fonte: autora, Fabricia Zulin.

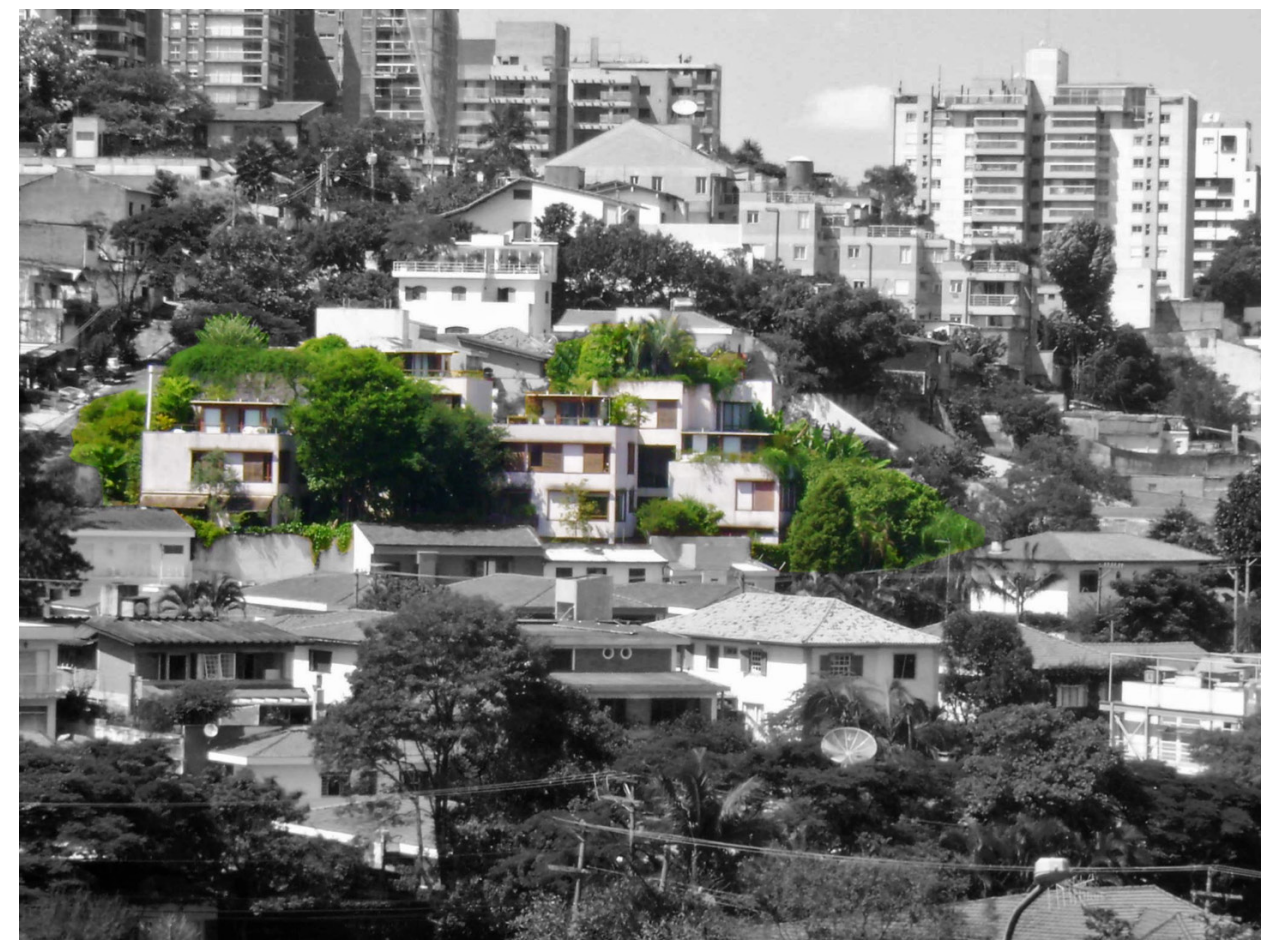




\section{Partido de implantação}

XAVIER (2012) informa que, ao contrário da maneira que havia sido feito no Fidalga 897, neste caso, o departamento de aprovação de projetos da prefeitura de São Paulo, determinou que as casas não poderiam ser sobrepostas, podendo, no máximo, tangenciar seus limites, diferentemente do que a própria lei cita:

Cada unidade habitacional ou a edificação formada por unidades habitacionais superpostas deverá ter no máximo 9,00 m (nove metros) de altura, medidos a partir do piso do pavimento mais baixo da unidade, incluindo o subsolo, até o limite superior da cobertura. (Lei 11.605, de 12 de Julho de 1994)

É importante mencionar a condução da aprovação de um projeto diferenciado como este, pois até os próprios funcionários da prefeitura tiveram dificuldade em entendê-lo e interpretá-lo dentro da lei; conjugou-se também à novidade que a lei representava. Assim, sem conhecimento prévio do projeto, ao caminhar pela vila, é possível ter a sensação que existe sobreposição de casas, no entanto, cada casa possui uma projeção individual no terreno, devido a uma condição da aprovação do projeto legal.

A topografia, principais vistas, a definição de acesso para veículos e pedestres, as orientações, a definição dos espaços coletivos e a legislação acabaram sendo os condicionantes na definição da localização e posição das unidades, ou seja, dos limites dos espaços privativos, numa distribuição tão particular quanto heterogênea, já que houve uma análise individual para cada unidade, como se fossem seis projetos diferentes e não um renque de casas iguais, como geralmente costuma ocorrer.

Assim, com relação à localização e posição das unidades, o projeto traz uma solução diferente das vilas tradicionais, geralmente com casas geminadas, viário comum frontal, e jardim individual, justamente devido a uma análise individual de todos os aspectos mencionados para cada unidade. É diferente também das soluções típicas de implantação das unidades isoladamente no terreno. Neste projeto, os limites das casas são dissolvidos e ao mesmo tempo entrelaçados, mesmo possuindo projeção individual. Estes limites, mesmo que sutis, são fortes o suficiente para não dar margem a uma apropriação individual imprópria de espaços definidos como coletivos pelo projeto, algo que no projeto Fidalga 897 ficou a desejar, já que houve situações de verdadeira "invasão" de espaço coletivo por usos privativos.

O conjunto não tem, assim, nem a escala nem a qualidade espacial de uma vila propriamente dita, mas de uma cidadela (não na acepção defensiva do termo, mas na idéia que ele indica de uma cidade concentrada - mais pela heterogeneidade dos espaços do que pela diversidade de equipamentos). (WISNIK, 2002)

Na Vila Fidalga, os espaços comuns e privativos são resolvidos com criatividade e geram condições particulares que a distingue de outros projetos. $\mathrm{O}$ acesso de pedestres às residências é feito por meio de um percurso que adentra o lote, chega a pátios de uso comum, passa por baixo de algumas casas, ladeia outras, atravessa o espaço coberto e, por fim, termina em uma viela que dá acesso à Rua Fradique Coutinho. Esta descrição expõe a heterogeneidade que os espaços possuem (Figura 6). 


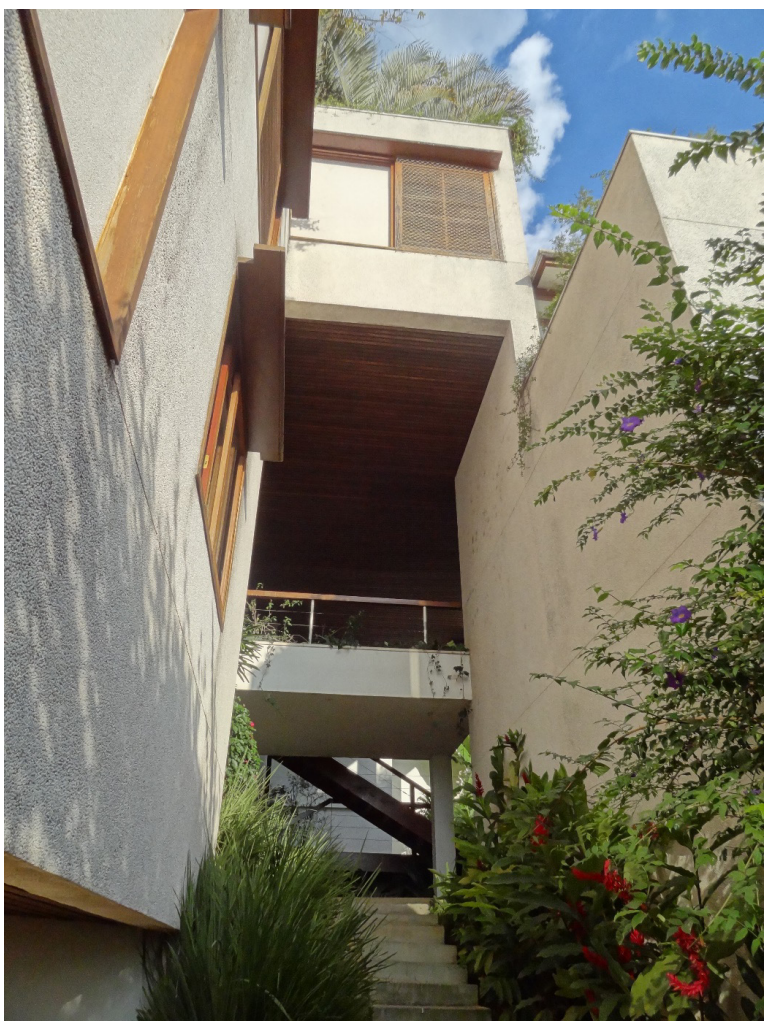

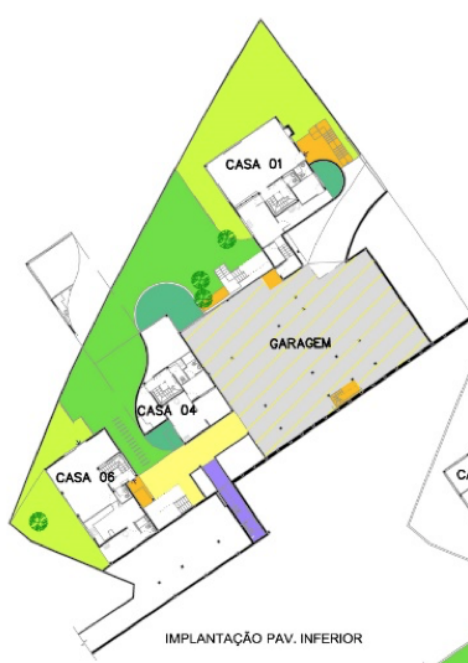

ESPAÇO EXTERIOR COLETIVO

PÁTIOS / CAMINHOS / PASSARELAS / ESCADAS

AREAS VERDES / JAROINS

\section{ESPAÇO EXTERIOR ENTRE} COLETIVO E PRÓPRIO

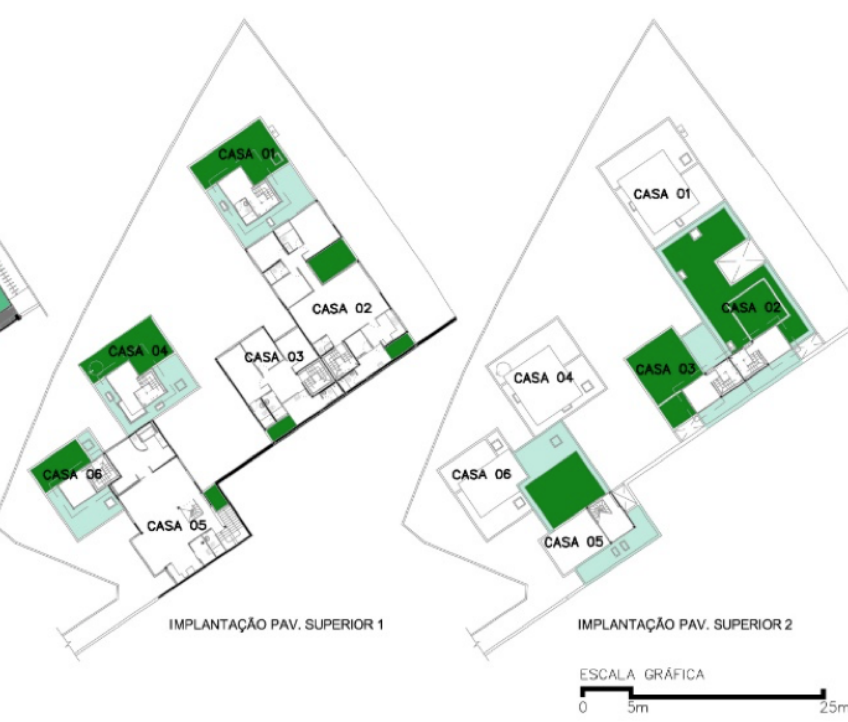

USOS NÃO RESIDENCIAL

$$
\text { VESTiBuLo EXTERno }
$$

JARDINS ENTRE COLETINO E PRIVATIVO
ESPAÇO EXTERIOR PRÓPRIO

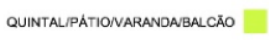

TERRAÇO NA COBERTURA JARDINS DE INTERESSE COMUM 
Figura 7: Vista desde o espaço exterior coletivo. Fonte: autora, Fabricia Zulin.
Os acessos de carros e pedestres são bem definidos e distintos. Com relação à definição dos acessos para veículos, a garagem fica na cota inferior, eliminando viário que cruza todo o terreno, e cada vaga fica próxima à entrada da casa correspondente, assim, responde a uma necessidade que os clientes geralmente pedem, porém, sem comprometer as áreas para convívio coletivo ou percursos peatonais, conforme será explicado a seguir no tema espaços exteriores.

\section{Espaços exteriores}

Foram identificados no projeto três tipos principais de espaços exteriores: de uso coletivo (pátios e jardins não privados); espaços entre o coletivo e o privativo, que funcionam como filtros entre estes espaços e possuem localização estratégica para garantia de privacidade entre área privativa e área comum; e por último, os espaços exteriores próprios, como quintais ou terraços privativos.

A identificação no projeto e destaque dos distintos espaços exteriores (Figura 7) possibilita a observação e sintetização de algumas táticas projetuais de resolução destes espaços. Pode ser observado, por exemplo na implantação do pavimento térreo, que todas as aberturas voltadas para o espaço coletivo, possuem algum elemento de filtro entre o espaço condominial e privativo da unidade, como por exemplo: amplas áreas ajardinadas protegendo as janelas e vestíbulos resguardando as portas de entrada das unidades habitacionais, enquanto os espaços coletivos de passagem estão juntos às paredes sem aberturas. Também vale ressaltar que a posição da garagem também vai ao encontro de preservar a privacidade das unidades, já que não há passagem de veículos na frente das casas.

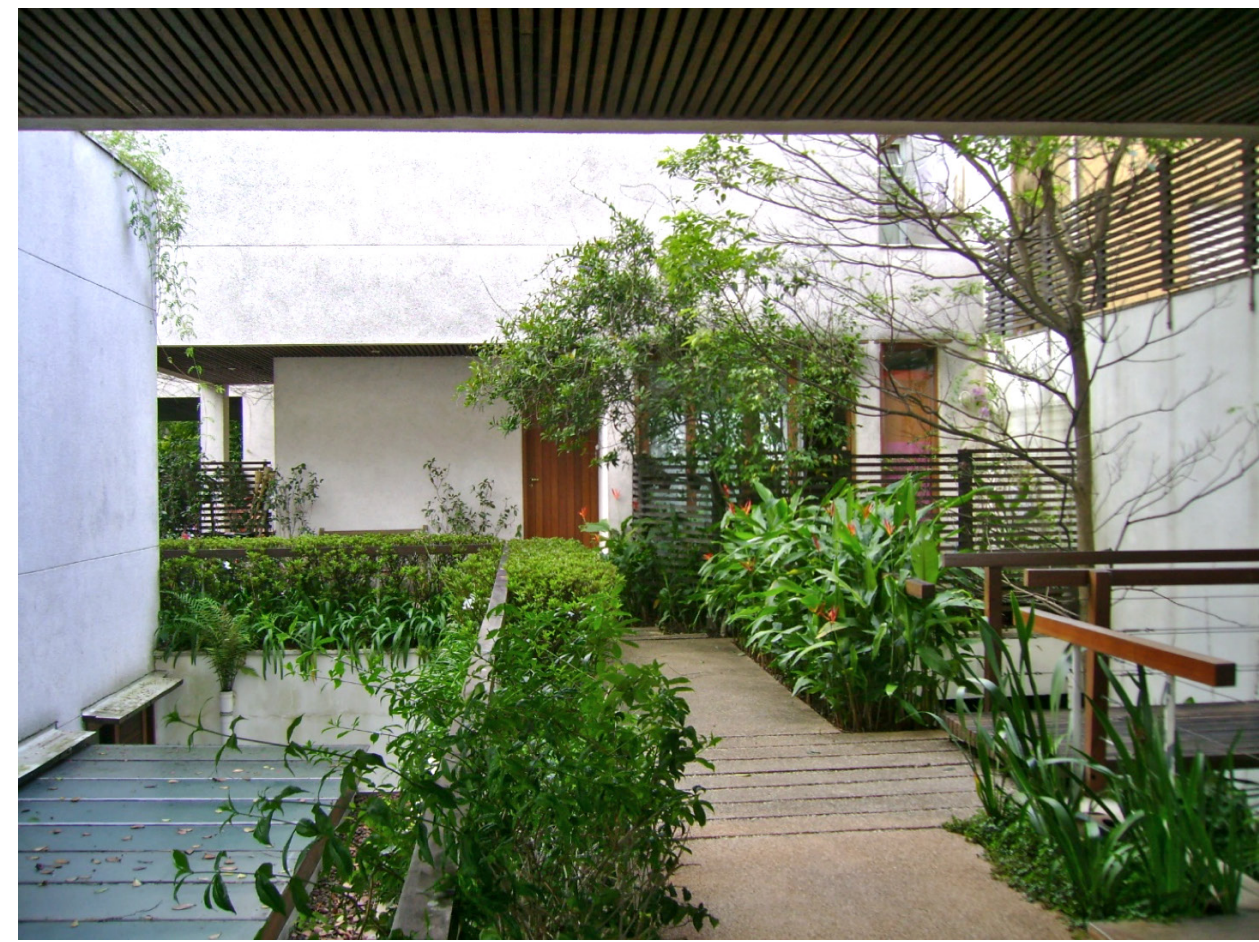


Assim, pode-se perceber, que os espaços exteriores, principalmente os coletivos, foram valorizados neste projeto, seja pela posição da garagem, como também pela diminuição de uma ou duas unidades a mais que o potencial do terreno possibilitaria. Porém, somada a área da garagem, que não deixa de ser um espaço com possibilidade para realização de atividades coletivas além de permitir acesso individual para cada unidade habitacional, chega-se a um valor acima da área total do terreno, e não conta como área computável. Assim, houve a tática de "criar terreno", de erguer as casas e ao mesmo tempo aproveitar melhor o espaço criado para uma destinação coletiva.

Desde a rua, pública, até a entrada das unidades, existem espaços estrategicamente posicionados de tal forma a não causar distúrbios nas áreas privativas. Por exemplo, antes da porta de entrada das unidades, transparece uma área com sensação de privativa, os vestíbulos. Deste vestíbulo externo, parece que tudo que está à volta é privativo, também por não ser possível enxergar portas ou janelas das outras casas (Figura 8).

Esta sensação interna de parecer que em determinados pontos exista apenas uma casa também é perceptível da rua: a sensação que dá é que existe apenas uma casa e não seis.

Algumas decisões de projetos demonstram o cuidado da arquiteta com relação à privacidade dos espaços ou bem-estar coletivo e individual. Por exemplo, foram previstas aberturas zenitais para os banheiros, afinal, trata-se de um espaço muito íntimo para possuir aberturas voltadas aos espaços coletivos. A solução criada para a captação e deságue das águas pluviais também exemplifica este cuidado. Não se percebem condutores lançando água pluvial nos passeios coletivos pois foi criada uma captação interna da água da chuva que cai no terraço da cobertura (existem quatros shafts no perímetro da caixa de escada interna de cada unidade), novamente respeitando o bom convívio no espaço comum.

Tais estratégias representam um papel pedagógico e regulador aos espaços de uso coletivo. Para identificar e definir estes diferentes setores, a arquiteta utilizou a tática de diferenciação a partir dos elementos construtivos: cercas de ripas para delimitar os jardins privativos; forros de madeira são utilizados nas áreas comuns e forros de gesso para espaços privativos com interferência no particular.

Em outras palavras, está contida no projeto da Vila a intenção de subverter duas práticas consolidadas na nossa sociedade, quais sejam, por um lado, o reiterado individualismo no uso dos espaços privados, e por outro, o imobilismo melancólico dos arquitetos acostumados a lamentar o fato de que a atividade projetual esteja, via de regra, refém das exigências redutoras da especulação imobiliária. (WISNIK, 2002)

\section{Unidade habitacional}

Algumas definições do projeto não poderiam ser modificadas durante o processo de vendas das unidades habitacionais: os acessos para veículos e pedestres; as áreas comuns; a garagem e a posição das vagas; o acesso às casas; o perímetro de cada unidade; enfim, questões relacionadas ao bom entendimento das orientações, topografia e principais vistas. Com relação ao espaço interior das unidades habitacionais, estava 


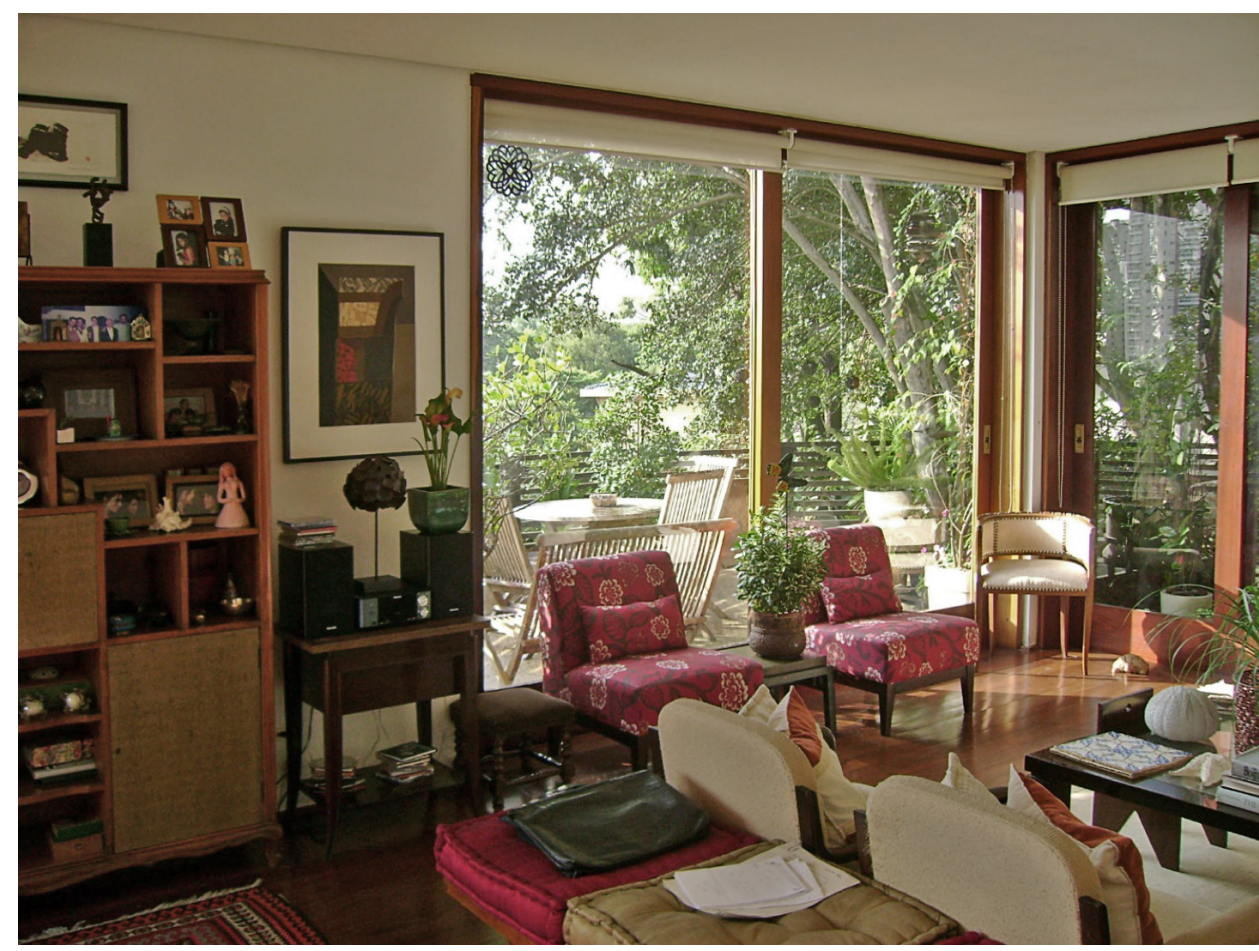

Figura 8: Vista do interior de uma unidade da Vila Fidalga. Fonte: autora, Fabricia Zulin. previamente definido no projeto: a posição da escada, que de certa forma centraliza também as instalações, já que possui shafts em seu perímetro com função de subida de água, descida de esgoto, descida de águas pluviais e também passagem das instalações elétricas. As áreas molhadas estavam pré-definidas, porém poderiam ser modificadas, desde que ficassem próximas da região da escada, por onde passam as instalações. Ainda com relação às unidades, estavam também determinados os níveis de laje e a área útil de cada pavimento. A estrutura, aberturas e acabamentos também eram elementos que o morador não poderia pedir modificações.

Assim, o atendimento personalizado ao morador, estaria limitado a algumas mudanças na distribuição programática interna, dentro do "casco" pré-determinado da unidade. A casa 01, por exemplo, teve um banheiro extra, no nível da cobertura; na unidade 05, haviam três quartos no projeto original da incorporação, mas o morador optou por apenas uma suíte e uma grande sala com um estúdio. Na unidade 03, foi colocada a lavandeira no andar superior, junto aos dormitórios, pois no térreo a moradora realiza seções de fisioterapia e, portanto, gostaria de ter mais espaço no térreo para receber melhor os clientes. Situações como estas aconteceram em todas as unidades, praticamente um atendimento personalizado, da mesma maneira que acontece quando um(a) arquiteto(a) realiza um projeto de casa unifamiliar para um cliente, postas algumas limitações necessárias para a viabilidade do empreendimento, visto que já houve um trabalho bem intenso da equipe de arquitetura para atendimento destes desejos individuais. Da mesma maneira que ocorreu no Fidalga 897, durante o processo de vendas, a arquiteta fazia alguns estudos rápidos de layout, para os clientes conseguirem visualizar as possibilidades espaciais antes de fechar o negócio. 
Estes croquis são elementos importantes de venda. Mas é importante lembrar que as dimensões das unidades não foram definidas pelos moradores, e que a variação tipológica está relacionada primeiramente ao estudo da orientação, principais vistas, entre outras avaliações já mencionadas. A definição interna dos ambientes com os futuros moradores colaborou para deixar as unidades ainda mais diversificadas.

Postas todas estas situações diversificadas do projeto, o que diferencia uma casa de um apartamento é justamente a liberdade de decisão de algumas questões, principalmente, programáticas por parte dos moradores. Uma casa dentro de um condomínio se diferencia de uma casa numa rua qualquer, justamente pela padronização que a acompanha. Assim, o desejo pela casa em lote individual é frequente à medida que as pessoas querem participar de algumas decisões do projeto, e assim, atitudes como estas adotada na Vila Fidalga, que criam algumas possibilidades de participação do usuário nas definições do layout interno em um limite condominial, ao menos abre o projeto à discussão e à possibilidade de atendimento a algumas particularidades dos moradores.

A forma da casa em que as pessoas estão sendo convidadas a viver não é um símbolo de si mesmas. (...) Embora possamos tornar os apartamentos maiores, com muitas das características de uma casa, bem como as oportudades de modificação e propriedade, ainda pode demorar muito tempo antes de a maioria das famílias americanas de renda baixa e média aceitarem isso como um Imagem válida de uma casa permanente. (MARCUS, 1995, p. 134, tradução nossa)

Este desejo pela liberdade ou personalização das habitações, parece ser uma vontade geral das pessoas, proveniente do desejo de uma aproximação mais humana da vida, dos pequenos sonhos e, assim como MARCUS (1995) coloca, um entendimento da habitação como símbolo de si próprias, e a Vila Fidalga consegue um resultado positivo neste sentido.

\section{Sistema estrutural e técnica construtiva}

Todas as unidades seguem a mesma solução construtiva: estrutura de concreto, composta por pilares de $25 \times 25 \mathrm{~cm}$, vigas de $14 \times 100 \mathrm{~cm}$, lajes maciças de 10 a $12 \mathrm{~cm}$ e fechamento em alvenaria. As pequenas construções nos terraços foram concebidas com estrutura de madeira jatobá, com pilares de $12 \times 12 \mathrm{~cm}$, vigas de $12 \times 20 \mathrm{~cm}$, fechamento em concreto celular e cobertura com manta impermeável sobre MDF.

A Ita Construtora executou e colaborou no desenvolvimento de alguns detalhes em parceria com a arquiteta, como a estrutura de madeira dos ambientes das coberturas e as abas de madeira das janelas.

Alguns materiais construtivos principais de acabamento ou peças complementares são encontrados neste projeto: madeira jatobá (caixilhos, guarda-corpos, decks, forros, escadas e último andar das casas) e agregado mineral jateado branco (fulget) nas paredes externas. Internamente, as paredes receberam massa única com pintura látex branca e nas áreas molhadas laminado melamínico branco texturizado. Ainda na parte interna, os pisos são assoalho de madeira e nas áreas molhadas granilite. 
Assim, com relação ao sistema construtivo como um todo, é possível notar principalmente que, mesmo se tratando de uma técnica construtiva convencional, os elementos em madeira diferenciam o comum de maneira muito coerente, fazendo seu uso nos locais ou em detalhes onde é possível fazer uma estrutura mais leve, como balcões, ambientes no terraço, escadas, passarelas, etc., contribuindo para uma execução mais limpa e rápida. Outro ponto é com relação à posição das instalações, de fácil acesso e não prejudicial ao convívio nos espaços coletivos, o que vai ao encontro da proposta da arquiteta em buscar um resultado final com garantia de bem-estar individual e coletivo.

\section{Envoltória}

Neste projeto diferente, por exemplo, do estudo de casos Fidalga 772 do escritório Andrade Morettin, a envoltória não se desliga da estrutura, afinal, ela é fundida ao fechamento e praticamente toda revestida por processos de masseamento. Ainda assim, existem qualidades na envoltória, capazes de agregar comunicação das unidades habitacionais com os espaços ao redor. As grandes aberturas no setor social, em conjunto com os balcões ou varandas externas, fazem com que a vista da cidade se misture ao espaço interior. No setor íntimo, o caixilho corre externamente à envoltória, permitindo cem por cento de ventilação, iluminação e visibilidade pelo vão. As janelas do setor de serviço, com exceção da cozinha, acabam se voltando para o espaço exterior próprio e, portanto, não são vistas desde o exterior coletivo, esta situação conjuntamente com a dos banheiros do setor íntimo, que possuem iluminação zenital, contribui ainda mais para a falta de clareza da divulgação do uso interno desde o exterior. Da mesma maneira que fica difícil identificar se são várias casas ou unidades sobrepostas, também fica difícil identificar os usos a partir das aberturas. Também percebe-se que o contato com o exterior é bloqueado propositalmente por algumas faces cegas das unidades para resguardar a privacidade de determinados usos privativos em relação aos espaços de uso coletivo.

Elementos arquitetônicos como janelas, persianas e varandas, bem como outros acabamentos, permitem essa conexão particular entre público e privado e tornam-se, ao mesmo tempo, elementos de composição que transmitem uma imagem distintiva do projeto. Sua natureza circundante não se limita a ser apenas um plano limite, mas pode se tornar o meio de comunicação do prédio com os espaços que o cercam. (BAHAMÓN e SANJINÉS, 2008, p. 134, tradução nossa)

Assim, a envoltória é o limite entre o público e o privado, como meio de comunicação do edifício com os espaços que o rodeiam, para o caso desta vila, mais significativo com os jardins coletivos e a própria vista à distância para a cidade, do que o contato próximo com a rua, já que as casas são mais relacionadas com o espaço coletivo criado dentro do limite do condomínio. O tratamento da envoltória com relação aos espaços coletivos foi pensado no sentido de estes serem conectados ou desconectados em colaboração com o bem-estar e coletivo, uma das grandes qualidades deste projeto. 


\section{Inserção urbana em lote urbano enquanto condicionante qualitativa do projeto}

Com relação à temática da inserção urbana, a avaliação final do conjunto de projetos a partir da análise das condicionantes do lote urbano é coerente com o raciocínio de seleção das obras, já que foram escolhidas aquelas com pouca possibilidade de replicação pela cidade e com projetos desenvolvidos para terrenos específicos, como bem demonstra o caso da Vila Fidalga.

A maioria dos lotes dos estudos de casos selecionados são cercados por terrenos vizinhos com apenas uma face significativa voltada ao viário público (Figura 9). Este tipo de situação em quadra urbana consequentemente proporciona situações de interferências do contorno do lote, edificações vizinhas e relação com a rua no partido arquitetônico do projeto.

Utilizando o método de análise gráfica, destacaram-se as seguintes características na tabela síntese (Figura 9):

- Implantação do lote na vista aérea em escala 1:2000, destacando seu contorno, projeção da edificação e destaque do viário de acesso ou que faz limite com o lote. Este desenho colabora na visualização da interferência do contorno do lote na definição do volume projetado sob o mesmo;

- Esquemas dos projetos em corte em escala 1:750, destacando o perfil topográfico natural e o definido no projeto do terreno, o número de pavimentos, volumes em corte e em vista (conforme posição do corte) e garagens subterrâneas. É importante a visualização da interferência do lote na definição do volume projetado também em corte, principalmente quando a alta declividade representa uma condição significativa no partido de implantação;

- Destaque em implantação e em corte das faces direcionadas às melhores visuais: em direção a vales, a massas arbóreas, etc.

- Destaque de algumas regras da legislação mais significativas.

Também, com base no conjunto de obras selecionadas e análise dos dados referentes aos projetos, foram identificados tamanhos distintos de lotes, tipos de declividade e formatos, conforme pode ser observado no quadro síntese "partido de implantação no lote urbano" (Figura 9).

Esta busca por uma identificação nos projetos de tamanhos, formatos e também inclinações topográficas distintas, foi com intenção de tentar verificar se, conforme colocado por DIEZ (2010), "formas inconvenientes" (irregulares), "escassas superfícies" (lotes pequenos), e também a topografia (pois São Paulo apresenta superfície muito acidentado), caberiam, supostamente, como condições relevantes para elaboração do projeto, e mais, se resultariam em projetos criativos e inovadores. Também, trata-se de terrenos geralmente evitados por empreendedores comuns, como por exemplo o caso da Vila Fidalga, situação na qual não ocorreu substituição de construção existente para implantação de um novo edifício, pois na verdade, representava vazio ou retalho urbano de pouco interesse para o mercado imobiliário, que precisava, de certo modo, da "valentia" e conhecimento da própria arquiteta como empreendedora de seu próprio negócio para assumir os riscos da situação atípica encontrada. 


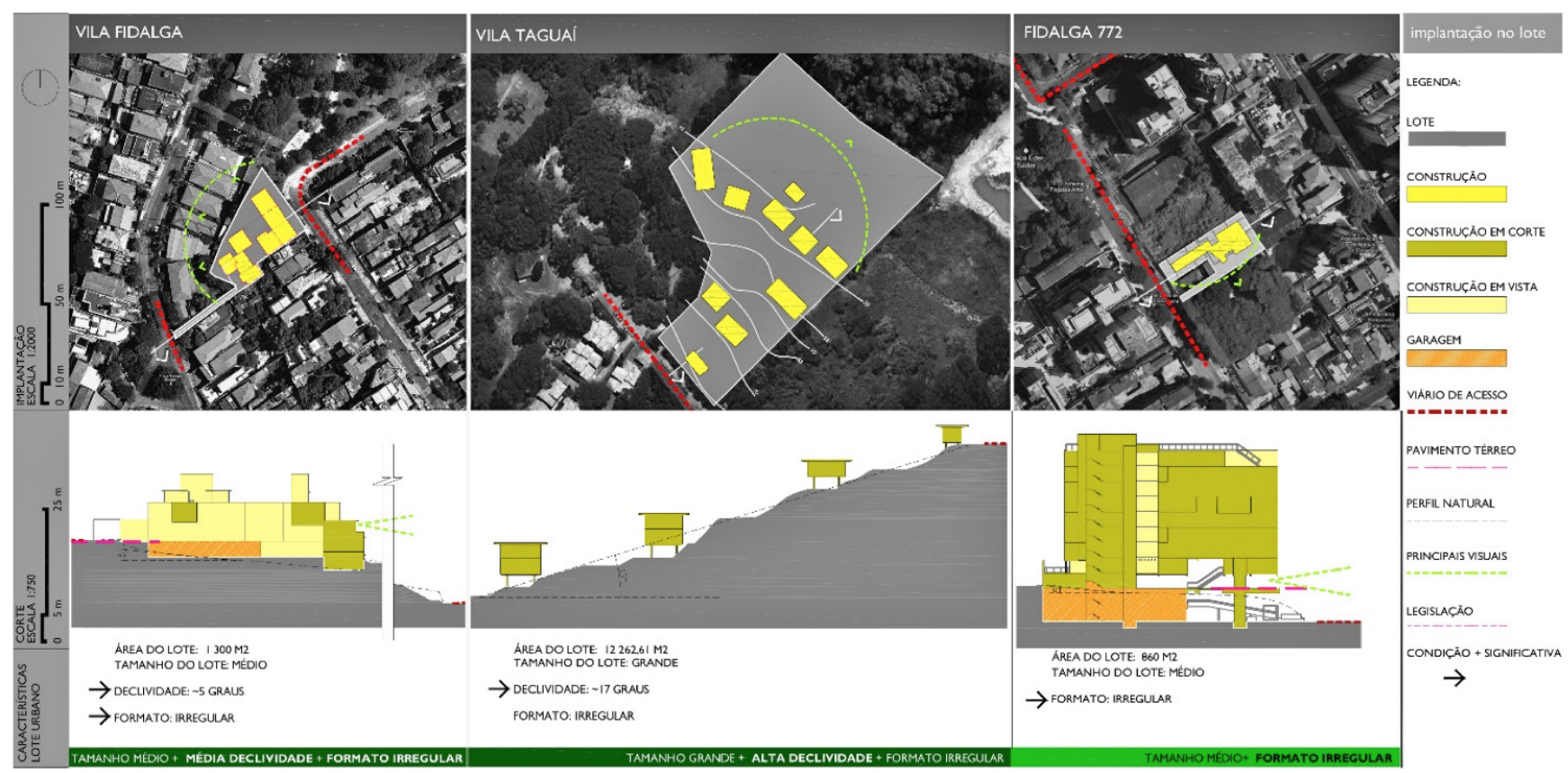

Figura 9: Tabela síntese "partido de implantação no lote urbano" com os seguintes projetos: Vila Fidalga, Vila Taguaí e Fidalga 772. Fonte: autora, Fabricia Zulin.
As táticas de infiltração requerem riscos. Como todo avanço em fronteiras desconhecidas, a exploração exige uma dose de coragem, bem como uma certa prudência e criatividade, trabalhando em áreas anteriormente evitadas por suas formas inconvenientes ou superfícies escassas, descobrindo novos locais em bairros negligenciados ou pouco conhecidos, propondo novos tipos de habitação que rompem com a partição convencional do espaço doméstico e espaços comunitários. (DIEZ, 2010, p. 35, tradução nossa)

Por fim, as obras foram sistematizadas na tabela síntese "partido de implantação no lote urbano" a partir de características significativas no partido arquitetônico de implantação comum entre alguns projetos. Enquanto demonstração dos resultados obtidos na pesquisa, para o presente artigo, consta tabela reduzida citando apenas alguns estudos de casos (Figura 9).

Utilizando como exemplo o estudo de caso Vila Fidalga, percebe-se que as condicionantes mais significativas da implantação foram:

1. Regras da legislação, afinal, as unidades habitacionais não poderiam ser sobrepostas, ou seja, os limites das unidades poderiam tangenciar-se, porém, todas as unidades deveriam ter projeção individual no lote;

2. Formato irregular do lote, por ser um lote considerado de porte médio o formato do mesmo é condicionante significativa na distribuição das casas no terreno, diferente, por exemplo de situações de terrenos maiores, como o caso da Vila Taguaí (Figura 9); 
3. Topografia, é bastante peculiar neste projeto a ausência de platôs principais que definem pavimentos tipo (térreo, primeiro e segundo pavimento cada qual com sua cota de nível única, por exemplo), diferentemente, as cotas de nível variam dentro de um mesmo "pavimento", especificamente em cada unidade habitacional;

4. Principais visuais, principalmente em direção a oeste e sempre levando em consideração a preservação da privacidade ou bem-estar coletivo e individual;

5. Orientações, prevalecendo aberturas nos quadrantes noroeste e nordeste.

Estas condições foram consideradas criteriosamente pela arquiteta autora do projeto, de tal modo a resultar em seis unidades habitacionais diferentes umas das outras. Cada parcela de terreno definido para cada unidade apresentava uma situação peculiar de vista principal, orientação e topografia que acabou permitindo pouca padronização do projeto arquitetônico das unidades.

\section{Considerações finais}

Na pesquisa realizada, a leitura individual e focada em cada projeto, (aqui representada pela Vila Fidalga), foi necessária e anterior a qualquer tipo de comparação, pois as obras possuem um conjunto de características e processos de realização muito particulares. No entanto, uma comparação final, como a demonstrada na tabela síntese "partido de implantação no lote urbano" (Figura 10) é também importante para evidenciar que as obras não pertencem a grupos tipológicos rígidos e sempre iguais, e sim, apresentam algumas ideias parecidas e que, não necessariamente por isso, irão pertencer em todos os temas ao mesmo grupo tipológico ou de sistematização geral do mestrado (Conjuntos Residenciais Horizontais, Edifícios pouco verticalizados com unidades habitacionais sobrepostas e Edifícios verticalizados com unidades habitacionais sobrepostas).

O trabalho também pode representar uma contribuição importante na busca por parâmetros de qualidade em projetos de habitação coletiva, visto que, atualmente, prevalece na paisagem das cidades uma arquitetura enfraquecida que possivelmente serve de referência a jovens ingressantes das inúmeras faculdades de arquitetura ou até os muitos profissionais já graduados. Assim, pesquisas sobre e por meio de projetos são necessárias como referência e incentivo a uma boa arquitetura.

Os exemplares da pesquisa conseguem aproximar duas situações possíveis para a arquitetura: uma arquitetura com qualidade, que coloca em prática conceitos aprendidos, verificados e em alguns casos, ensinados na academia (já que muitos arquitetos(as) atores(as) protagonistas desta pesquisa são docentes em universidades de arquitetura); com uma arquitetura voltada a uma necessidade prática.

Por fim, os estudos de casos representam uma pequena parcela de produce de arquitetura contemporânea com propósitos diferenciados, já que foram realizadas por varios(as) arquitetos(as), cada um(a) com sua linguagem e repertorio próprio(a); concebida por diferentes agentes; em terrenos e localidades com condicionantes variadas; com programas específicos; com consideração das varias posibilidades de 
técnicas construtivas e mão de obra disponível; para atendimento aos diferentes desejos e necesidades pessoais; enfim, uma produção que não foi configurada, segundo WILHEIM (2008), pela "mão escondida", protagonista que desenha plantas com dimensões iguais, que desenha sempre as mesmas fachadas, com os mesmos tons de bege, cuja autoria raramente é divulgada.

\section{Referências bibliográficas}

BAHAMÓN, Alejandro; SANJINÉS, María Camila. Alta densidad: Vivienda Contemporánea. Barcelona: Parramón ediciones, 2008

DIEZ. Fernando. Tácticas de Infiltración. SUMMA+, Buenos Aires, n.107, p.34-39, abril de 2010.

WISNIK, Guilherme. O espaço coletivo como baliza. Revista Novos Estudos - CEBRAP, São Paulo, n. 64, novembro de 2002.

MARCUS, Clare Cooper. House as a Mirror of self: Exploring the Deeper Meaning of Home. Lake Worth, FL: Nicolas-Hays, 2006.

TEPERMAN, Sérgio. Boa Arquitetura. Arquitetura e Urbanismo, São Paulo, n. 185, p. 79, agosto de 2009.

WILHEIM, Jorge. Mão escondida projeta arquitetura medíocre. São Paulo: Vitruvius, 096.04, julho 2008. Disponível em: <http://www.vitruvius.com.br/revistas/read/arquitextos/>. Acesso em: 04/02/2013.

ZULIN, Fabricia. Habitar Coletivo. Obras diferenciadas contemporâneas em São Paulo. 2013. 521 p. Dissertação (Mestrado em Arquitetura e Urbanismo), Universidade de São Paulo, São Paulo, 2013

Leis

BRASIL. Lei $n^{\circ}$ 11.605, de 12 de julho de 1994: Dispõe sobre a criação da subcategoria de uso residencial R3-03, conjunto residencial - vila, e dá outras providências. Brasília, DF, 1994.

\section{Entrevista}

XAVIER, Cristina. Cristina Xavier: depoimento [dez. 2012]. Entrevistadora: Z. Fabricia. Entrevista concedida para realização da dissertação de mestrado: Habitar Coletivo. Obras diferenciadas contemporâneas em São Paulo, defendida na Faculdade de Arquitetura e Urbanismo da Universidade de São Paulo no ano de 2013.

\section{Complementares}

XAVIER, Cristina. Memorial Projeto Vila Fidalga. 2001

ZULIN, Fabricia. Visita Vila Fidalga com arquiteta Cristina Xavier [abr. 2011].

ZULIN, Fabricia. Visita Vila Fidalga [maio 2012]. 